Article

\title{
Directionality across Diversity: Governing Contending Policy Rationales in the Transition towards the Bioeconomy
}

\author{
Lisa Scordato $^{1, *}$, Markus M. Bugge ${ }^{1}$ and Arne Martin Fevolden ${ }^{2}$ \\ 1 Nordic Institute for Studies in Innovation, Research and Education (NIFU), P.O. Box 2815 Tøyen, \\ NO-0608 Oslo, Norway; markus.bugge@nifu.no \\ 2 Centre for Technology, Innovation and Culture (TIK), University of Oslo, P.O. Box 1108 Blindern, \\ NO-0317 Oslo, Norway; arnemf@tik.uio.no \\ * Correspondence: lisa.scordato@nifu.no; Tel.: +47-454-307-75
}

Academic Editor: Teis Hansen

Received: 30 November 2016; Accepted: 25 January 2017; Published: 3 February 2017

\begin{abstract}
Although the bioeconomy has been embraced by many governments around the world as a way of responding to the grand challenge of climate change, it remains unclear what the bioeconomy is and how it can contribute to achieving these broad policy objectives. The aim of this paper is to improve our understanding of whether, and how, the bioeconomy includes contending rationales for governance and policy-making. In order to do this, we apply a typology of three bioeconomy visions onto the policy discourse on the bioeconomy. These visions are (1) a bio-technology vision; (2) a bio-resource vision; and (3) a bio-ecology vision. Based on a discourse analysis of 41 submissions to a public hearing on the development of a bioeconomy strategy in Norway, the paper explores the actors involved in shaping the new bioeconomy and analyses their positions on this emerging field. The paper finds that it is possible to categorise the consultative inputs into these three visions, and also that the bio-resource vision is predominant, which reflects the structure of the national economy. Moreover, the paper reflects upon how the contending visions observed imply negotiations and power struggles, which may hamper directionality in the current socio-technical transition.
\end{abstract}

Keywords: governance; bioeconomy; policy; innovation; power; directionality

\section{Introduction}

One of the pressing societal challenges today relates to climate change and the need to replace fossil-based inputs with renewable resources in the production of fuel, energy, and chemical compounds. This has resulted in the development of biofuels, such as bioethanol, biodiesel, and biogas; bio-products, such as bio-plastics, bio-chemicals, and bio-pharmaceuticals; and bioenergy, such as electricity and district heating generated at biogas or combustion plants. The magnitude and diversity of these initiatives have led scholars, commentators, and policy-makers to talk about a 'bioeconomy' and, subsequently, to call for a more comprehensive policy framework to support and direct this emerging field of the economy. The bioeconomy concept has been embraced by many governments around the world with a view to responding to diverse societal challenges, including not only solving issues related to climate change, but also dealing with areas such as food security, resource efficiency, and health problems [1,2]. Nevertheless, it remains unclear what the bioeconomy is, and how it can contribute to achieving these broad and potentially contending policy objectives.

In recent years, a growing body of academic literature has emerged that aims to understand the roles of the bioeconomy in mitigating the challenges of climate change, and which also tries to disentangle the notion of the bioeconomy and its implications for governance. A recent contribution 
from Bugge et al. shows that the notion of the bioeconomy is multifaceted and covers several sectors and meanings, including different "rationales or visions of the underlying values, directions and drivers of the bioeconomy" [3]. Opposing rationales may also reflect the diversity of the sectors and policy areas involved, which stresses the need for horizontal policy mixes across sectors [3].

Theorising on the governance of socio-technical transitions has emphasised the need for an active state, formulating societal needs and establishing the direction in socio-technical transitions.

The urgent need for green innovation requires policies that are not merely designed to improve coordination and fix market failures, but that are based on clear strategies aimed at reducing the risks and uncertainties in the field $[4,5]$. At the same time, it is increasingly acknowledged that, when compared with traditional policy fields, challenge-oriented policy measures require more demand-side policies, such as public procurement stretching across policy domains. Finally, it is assumed that the coordination and reflexivity needed in such societal transitions can be perceived as a form of meta-governance. The involvement of a broad range of actors in agenda setting is perceived as crucial. A pertinent question, however, is what the implications of such participative governance suggest, in terms of the possibilities for policy-makers to direct transitions in an effective and efficient way.

Against this background, the aim of this paper is to improve our understanding of whether and in what way the bioeconomy consists of contending rationales for governance and policy-making. In order to do this, we apply a typology of three visions of the bioeconomy onto the policy discourse on the bioeconomy. This typology distinguishes between (i) bio-technology visions, emphasising the importance of biotechnology and its commercial applications; (ii) a bio-resources vision, focusing on processing and upgrading biological raw materials, as well as establishing new value chains; and (iii) a bio-ecology vision, which highlights sustainability and ecological processes, including biodiversity. This typology was created by Bugge et al. [3] through an extensive review of the scientific literature that dealt explicitly with conceptual aspects of the bioeconomy, focusing on areas such as innovation and value creation, driving forces, governance, and the spatial implications of the bioeconomy.

The paper applies these visions onto a number of submissions in a public inquiry process on the development of a national strategy for the bioeconomy in Norway. Through the analysis, the paper seeks to depict (a) the types of actors involved in shaping the direction of the new bio-based economy and (b) their positions on this emerging field. Based on this analysis, the paper discusses the implications and possibilities for governance in setting the direction for the current socio-technical transition.

The article is structured as follows: in Section 2, we describe the conceptual framework for the analysis. Section 3 will then outline the approach and methods used to analyse the empirical material. In Section 4, some background on the Norwegian economy is outlined. The results from the analysis are presented in Section 5. Finally, Section 6 concludes the paper by summing up the findings and reflecting upon their implications.

\section{Conceptual Framework}

Over the last couple of decades, there has been increasing interest among innovation scholars and policy-makers in grand challenges and socio-technical transitions [6-11]. Such societal challenges and system transformations are seen as open-ended and constantly redefined and renegotiated across several sectors and stakeholders [8]. In the search for possible solutions to these highly-integrated and complex societal challenges, it has been pointed out that there is a need for an "opening up" of decision-making processes, in order to include participation from a broader array of societal stakeholders. One concrete example of such an open approach is the use of public hearings to develop policy strategies, alongside consensus conferences and foresight exercises, as well as other approaches, in order to make decision-making processes more open and inclusive $[12,13]$.

Such integrative approaches to policy making can be demanding. They require the coordination and processing of complex and often conflicting inputs from a broad array of actors. Weber and Rochracher [5] have developed a framework for legitimising policies addressing grand challenges, and 
operating with four required roles for governance in societal transformations: directionality, demand, coordination, and reflexivity. Directionality failure refers to a deficit in the pointing of innovation efforts and collective priorities in a certain direction to meet societal challenges. Demand articulation failure refers to a deficit in anticipating and learning about user needs, resulting in inappropriate and misleading specifications guiding development through, e.g., procurement or policy programs. Policy coordination failure refers to a deficit in managing and synchronising the inputs from different policy areas to meet societal challenges. Such coordination might include coherence between policies at international, national, regional and municipal levels (vertical coordination failure), or across different sectors (horizontal coordination failure). Reflexivity failure refers to a deficit in the learning feedback loops and in the ability to continuously monitor the progress of ongoing innovation processes and to adjust the course of action. Alongside the existing categories of market and system failures, such forms of transformational system failures constitute a more comprehensive framework and legitimacy for policy intervention and formulation. In general, the role for governance in addressing socio-technical transitions is seen as more proactive and entrepreneurial than as has traditionally been regarded the norm for state intervention, in terms of fixing market failures or system failures $[9,14]$.

Still, although the state is expected to take a leading role in these processes of societal transformation, there is reason to question whether and how these four roles (i.e., setting the direction, formulating demand, coordinating various stakeholders, and ensuring continuous learning and reflexivity) only constitute an extension of the former technocratic policy framework associated with systems of innovation in terms of fixing system failures. Rather, one may argue that societal shifts like the transition into a sustainable bioeconomy represent conflicting rationalities and perspectives that transcend the coordination of various inputs sharing the same societal ontology and objectives. In this sense, there are potential challenges related to navigating in a landscape consisting of diverse stakeholders. Governance across heterogeneous interests poses challenges for policy-makers and complicates strategy-making processes. Various stakeholders might express diverging and conflicting interests which, again, might lead to power struggles and negotiations.

A prominent approach to understanding socio-technical transitions involving diverse stakeholders is the multi-level perspective (MLP), which sees systemic transitions as co-evolutionary processes that unfold through an interplay between three interrelated analytical levels: regimes, niches, and landscapes [6,15-18]. A socio-technical regime refers to the existing configurations of technologies, infrastructures, production processes, practices and consumption patterns. Niches are seen as the locus for the development of disruptive innovation to supplement or replace existing socio-technical regimes. Finally, landscapes refer to the contextual and long-term societal trends that create pressures on existing socio-technical regimes, thus causing windows of opportunity for innovative niches.

Although the MLP perspective has advanced our understanding of socio-technical transitions, it has also been criticised for putting too much emphasis on the emergence of niches as the principal locus for regime change [17]. Much of the MLP literature has also tended to focus upon the emergence of new regimes, and less is said about the decline of existing and old regimes [19,20]. Moreover, it has been pointed out how theorising on socio-technical transitions has traditionally downplayed the role of power relations and politics in many ways [20]. First, there has been a lack of focus on how power relations affect the development of policies in socio-technical transitions. Second, there has been a tendency to focus on the development of innovative niches rather than on the destabilisation of existing regimes. Third, the stability of existing regimes is often understood and explained in terms of socio-technical configurations and user practices related to notions, such as lock-in and path dependence, rather than political priorities and deliberate decisions [20]. In sum, there is a need to improve our understanding of how (political) power relations and negotiations affect directionality in the processes of socio-technical transitions.

In an effort to address these shortcomings, throughout the last decade there has been increased interest in better understanding the power struggles and institutional underpinnings involved in socio-technical transitions [20-25]. Some of these contributions have started to pay attention to the 
stability of existing socio-technical regimes, and to how the incumbent actors and stakeholders of existing regimes show resistance to niche innovations and developments that threaten the status quo (e.g., [20]). In this sense, power and politics have increasingly started to be seen in connection with the multi-level perspective, with the actors of existing socio-technical regimes treated as actively resisting change and protecting their current positions in the existing regime.

\subsection{Contending Visions on the Bioeconomy}

The notion that grand challenges transcend sector boundaries is especially relevant in the case of the bioeconomy. The development of a bioeconomy represents a move from fossil-based to bio-based products, fuel, and energy, and can, therefore, be seen as a way to address the grand challenge of climate change. However, the notion of the bioeconomy can also be seen to address other grand challenges related to food security, health, industrial restructuring and energy security [26-28]. The bioeconomy can thus be seen as a generic phenomenon spanning a broad range of technologies and sectors of the economy, such as the agriculture, marine, forestry, bioenergy, chemicals, materials, and health sectors. Nevertheless, it is important to stress that a transition to a sustainable bioeconomy does not constitute a predetermined path, but still remains an open, future possibility. It is not something that will necessarily happen, and it will only occur through considerable and coordinated efforts, which will involve a wide range of actors. The bioeconomy has been conceptualised by previous scholars as a particular policy ambition and framework [29,30], representing "a techno-economic imaginary of the future that is co-produced with certain policies, institutions, and infrastructures that are framed as desirable and possible, while others are framed as undesirable and problematic" [31].

Richardson [28], among others, found considerable difference of opinion between "farmers and agribusiness, between those convinced and those sceptical of environmental technofixes, and between procorporate and anti-corporate NGOs" with regards to the use of biotechnology [28]. The tensions arising from biotechnology innovations have also been emphasised by De Witt et al. [32]. Conflicting lines exist around the genetic modification of food, bio-based products, and pharmaceuticals [32]. Levidow et al. [29] argue that the concept of the bioeconomy is still rather new and is not yet explicitly integrated into policy-making. In this regard, they suggest that policy strategies which declare the intentions and visions for the development of a bioeconomy may have an important role towards achieving a transition towards the bioeconomy, and in determining the direction of the transition, in terms of the funding, instruments and involved organisations $[29,30,33]$. On the other hand, Bosman and Rotmans found that the governments that have adopted bioeconomy policies already have approached this policy area quite differently — with the Dutch government acting as a 'facilitator' and the Finnish government as a 'director of transition' for the bioeconomy, for instance [34]. The novelty of the bioeconomy as a concept has also been stressed by Hilgartner [35]. In a critical analysis of the definition of the bioeconomy promoted by the Organisation for Economic Co-operation and Development (OECD), he argues that this has created "a new policy-oriented machinery suited to the work of ongoing technoeconomic anticipation" [35] (p. 385). At the same time, he raises critical concerns for how the bioeconomy definition of the OECD takes "economic operations as its distinctive focus", as this places other policy fields, such as the environment, health, and agro-food, in secondary positions. He therefore calls for a "reflexive examination" of a highly political concept, as the bioeconomy as a policy field has emerged to be [35]. In sum, this suggests that the notion of the bioeconomy has developed as a complex and highly contested policy field.

Although subject to increasing interest in the last decade, there is, thus, still little clarity in terms of what the notion of the bioeconomy implies and means. In an attempt to improve our understanding of the different perspectives on the bioeconomy, Bugge et al. [3] have distinguished between three visions of what the bioeconomy constitutes. The three visions are (1) the bio-technology vision; (2) the bio-resource vision; and (3) the bio-ecology vision.

The bio-technology vision emphasises the importance of the application and commercialisation of bio-technology in different sectors. The objectives of the bio-technology vision relate to economic growth and job creation $[2,36]$. Value creation is based on the application of biotechnologies in various 
sectors, as well as on the commercialisation of research and technology within the framework of a globalised economy. As such, the bio-technology vision is in many ways similar to the so-called linear model of innovation, where a science push is seen as the primary driver of innovation and economic growth. Within this vision, close interaction between universities and industry is needed in order to commercialise relevant research [37].

The bio-resource vision focuses on the processing of bio-based resources as the primary driver and objective for innovation and economic growth. Whereas economic growth in the bio-technology vision is based on capitalising on biotechnologies, growth in the bio-resource vision is expected to come from capitalising on bio-resources. Value creation in the bio-resource vision emphasises the processing and conversion of bio-resources into new products. In addition to an optimisation of land use and existing value chains, waste management and the development of new value chains are also important in this vision. Moreover, the role of research, development, and demonstration (RD and D) is central. Whereas the bio-technology vision takes a point of departure in the potential applicability of science, the bio-resource vision emphasises the potential of upgrading and converting the biological raw materials.

The bio-ecology vision highlights the importance of ecological processes that optimise the use of energy and nutrients, promote biodiversity and avoid monocultures and soil degradation. While the first two visions are technology-focused and assign a central role to RD and D in globalised systems, this vision emphasises the potential for locally- or regionally-integrated, circular processes, and systems. In contrast with the importance of external linkages in the first two visions, the bio-ecology vision calls for the development of locally-embedded economies in the form of "place-based agri-ecological systems" [38], as a central characteristic for ensuring a sustainable bioeconomy.

The three visions are seen as analytical categories, and should, thus, not be considered as completely distinct from each other, but rather as ideal-type visions of the bioeconomy. Similar analytical categories have also been used in previous studies of the national discourses and narratives of the emerging bioeconomy. Birch [31], for instance, analyses policy visions and frameworks in the Canadian bioeconomy by applying four distinct definitions of the bioeconomy: (1) product based; (2) substitution; (3) renewable-versus-sustainable; and (4) societal transition. Like the visions framework used in this paper, Birch finds that one of the definitions (societal transitions) represents a competing alternative to the others, and this represents an example of the tensions and conflicts that exist in developing the bioeconomy [31]. In our case, this alternative is represented by the bio-ecology vision.

In order to test the relevance of this conceptual framework, we wish to apply it onto a number of submissions to a public hearing process that was part of the development of a national strategy for the bioeconomy in Norway. By doing so, we wish to see whether the different visions on the bioeconomy that were earlier identified in a review of the research literature can also be found among other types of civic and business stakeholders in the bioeconomy. This exercise will, thus, test the analytical framework applied, as well as improving our understanding of the power struggles and politics in socio-technical transitions.

\section{Materials and Methods}

The method for the analysis is based on a discourse analysis of a recent national public inquiry process for a bioeconomy strategy in Norway. The public inquiry was initiated by the Ministry of Trade, Industry and Fisheries and the Ministry of Food and Agriculture in 2015. The inquiry was launched with the aim "to identify overall priorities for a national strategy within the field and formulate goals and instruments in a long term perspective". Parties were invited to submit their opinions by sending in written submissions. The public inquiry material comprises of 41 written submissions made by as many different actors representing private companies, industry associations, universities and university colleges, research institutes, interest organisations, municipalities, and NGOs. Most of the written submissions were about two pages long, whereas a few were detailed reports of up to 13 pages, with annexes.

Although a considerable number of written statements were submitted, it remains an open question whether or not these statements reflect the opinion of all the stakeholders in the bioeconomy. 
Some stakeholders might not have learned about the public inquiry process and others might not have felt sufficiently competent to express their opinion publicly. Nevertheless, we believe that both the variety of submissions and the extensive participation of interest organisations and NGOs suggest that the public inquiry process gathered a fairly broad and balanced selection of different stakeholders' opinions.

The text analysis was carried out in two main steps. First, the submissions were categorised by actor groups and sectors (Figure 1). Second, the text elements were coded according to the applied predefined bioeconomy visions [3] and a corresponding set of sub-topics (Table 1). In this way, the text corpus was systematically analysed, allowing us to identify emerging discursive patterns.

In sum, the discourse analysis was carried out through a bottom-up and iterative process of the identification, interpretation and categorisation of (a) actors; (b) their statements and advice; and (c) their visions on the bioeconomy (At the time of writing, the Norwegian bioeconomy strategy was not yet published.).

Table 1. Key characteristics of the bio-economy visions [3].

\begin{tabular}{|c|c|c|c|}
\hline & The Bio-Technology Vision & The Bio-Resource Vision & The Bio-Ecology Vision \\
\hline Value creation & $\begin{array}{l}\text { Application of biotechnology, } \\
\text { commercialisation of research } \\
\text { and technology }\end{array}$ & $\begin{array}{l}\text { Conversion and upgrading of } \\
\text { bio-resources (process oriented) }\end{array}$ & $\begin{array}{l}\text { Development of integrated } \\
\text { production systems and } \\
\text { high-quality products with } \\
\text { territorial identity }\end{array}$ \\
\hline $\begin{array}{l}\text { Drivers and } \\
\text { mediators of } \\
\text { innovation }\end{array}$ & $\begin{array}{l}\text { R and D, patents, TTOs, } \\
\text { Research council funders } \\
\text { (Science push, linear model) }\end{array}$ & $\begin{array}{l}\text { Interdisciplinary, optimisation of } \\
\text { land use, include degraded land } \\
\text { in the production of biofuels, use } \\
\text { and availability of bio-resources, } \\
\text { waste management, engineering } \\
\text { science and market (interactive } \\
\text { and networked production mode) }\end{array}$ & $\begin{array}{l}\text { Identification of favourable } \\
\text { organic agro-ecological practices, } \\
\text { ethics, risk, transdisciplinary, } \\
\text { ecological interactions, re-use } \\
\text { and recycling of waste, land use, } \\
\text { (circular and self-sustained mode) }\end{array}$ \\
\hline
\end{tabular}

We use three ideal visions of the bioeconomy to identify the prevailing and potentially contending understandings of what the bioeconomy constitutes, and the diverse bases and perspectives that actors may have on this field. The ideal types are used as a method of interpretative analysis for understanding the way actors and organisations view a defined context, and to facilitate comparisons. In this sense, ideal types do not conform completely to reality, but are simplified models of interpretation [39]. Moreover, these visions should not be considered to be completely distinct from each other, but interrelated [3]. Table 1 illustrates the key characteristics of the three bio-economy visions, with their respective implications in terms of overall aim, value creation, drivers and mediators of innovation, and spatial implications. Hence, we expect that these visions also co-exist across heterogeneous bioeconomy stakeholders.

Although Bugge et al.'s [3] bioeconomy visions constitute a useful tool for classifying the written submissions to the public inquiry process, there are also some methodological challenges related to applying these visions onto new contexts. First, the visions were primarily created based on analysing academic articles, and these might not express ideas and ideals that are prevalent among NGOs, industry associations and private companies. Second, the visions reflect the scientific discourse through the last decade and, thus, refer to ideas that were sometimes expressed many years ago, which might not be equally relevant for processes that are ongoing today. Nevertheless, we believe that these potential methodological challenges are minor, and that we were able to deal with them effectively by carefully reading and cataloguing the written inputs to the public hearing. 


\section{Background}

Over the past century, Norway has developed a strong resource-based economy. It has established strong industries within forestry, aquaculture, and petroleum, and these resource-based industries have typically accounted for about $80 \%-90 \%$ of the country's exports. Nevertheless, the relative importance of these natural resource sectors has varied over time [40]. In the early 1900s, the prominent export products were fish and wood, in addition to relatively smaller quantities of paper and minerals [41]. Today, the most prominent export products are oil and gas and related petroleum products, in addition to relatively smaller quantities of fish and metals (see Statistics Norway). If we look specifically at bio-resources, fish was already an important export product in the early 1900s and is, today, by far the largest bio-based export product. Wood products were important in the early 1900s, but have lost much of their market share in the past decade. Agricultural products, on the other hand, have never been exported in large quantities. Seen together, this development path has created an imbalance in the Norwegian bioeconomy, in which the seafood sector can be described as an export leader that is seeking to expand its markets abroad; the agricultural sector can be described as an export lightweight that is seeking to protect its domestic markets from foreign import; and the forestry sector can be seen as a struggling has-been that is seeking to find new ways of regaining some of its former glory.

Although many resource-based economies have become victims of the "resource curse", Norway has-along with a few other countries, such as Australia-been able to reach modern levels of development while relying extensively on the extraction and refinement of natural resources. Ville and Wicken argue that what distinguishes the successful from the less successful resource-based economies is their ability to diversify into new "resource products and industries", through a dynamic interplay between the natural resource industries and the knowledge-producing and disseminating sectors within their societies [40]. Ville and Wicken describe these knowledge-producing and disseminating sectors as 'enabling sectors' that are typically comprised of capital goods suppliers and R and D institutions, and they maintain that a healthy interplay between these enabling sectors and the natural resource industries leads to both improved productivity in old resource-based sectors and the development of new resource-based industries. For instance, they found that the development of a strong mechanical engineering industry played a crucial role in establishing a vibrant Norwegian wood processing industry, and that Norwegian marine biologists helped the fisheries develop and make use of new fishing methods, thereby improving their productivity [40].

Today, this dynamic interplay between the enabling sectors and the natural resource industries define the working of Norway's bioeconomy. In terms of $\mathrm{R}$ and $\mathrm{D}$ institutions, most of the Norwegian bio-industries rely on a range of well-developed scientific institutions. The seafood industry benefits from research carried out in as many as 20 semi-public and private research institutes, of which some of the most important institutions include the Norwegian Veterinary Institute and the Norwegian College of Fishery Science [42]. The agriculture and forestry industries also rely on strong academic institutions-such as the Norwegian University of Life Sciences (NMBU) and the Norwegian University of Science and Technology (NTNU)—both of which carry out a considerable amount of relevant $\mathrm{R}$ and $\mathrm{D}$ [43]. In terms of capital goods suppliers, the seafood industry has a much more developed industrial base to draw upon nationally than the agriculture and forestry industries. The seafood industry —and in particular the aquaculture sector-can rely on a large group of mostly small and medium sized suppliers that carry out a substantial amount of R and D, and it is generally considered to be at the technological forefront of this area globally [42]. The agricultural and forestry sectors, on the other hand, rely on national suppliers that import much of the equipment from foreign companies and carry out a limited amount of development work at home [43]. The natural resource industries and enabling sectors can be described as the prime carriers and promoters of the three bioeconomy visions described above [3]. Together, they comprise the core of the Norwegian bioeconomy and the policy positions they advocate reflect, to a large extent, their position within the wider Norwegian economy. 


\section{Findings}

Based on the discourse analysis of the different texts submitted to the public inquiry on Norway's bioeconomy strategy, we have been able to identify discursive patterns which relate to the three bioeconomy visions [3]. The three bioeconomy visions are crucial elements in this analysis, as they reveal the tendency for both conflicts and alignments between the participating actors. As we discussed above, the various bioeconomy visions differ in terms of aims and objectives, as well as over which might or might not be compatible as guideposts for a future bioeconomy. It is, therefore, interesting to see to what extent the different actors commit themselves to these bioeconomy visions and how the visions become manifested in terms of specific policy suggestions. It is also interesting to see whether certain actor groups commit themselves to specific visions and if these groups are large and powerful enough to influence the direction or pace of the transition process towards the bioeconomy.

Regarding the participating actors, we find that more than half of the submissions were from industry associations or private firms, followed by an even distribution of other actor groups representing public authorities, academia, and environmental and social NGOs. When further dissecting the private sector group, we find that they represent a multitude of industrial sectors ranging from forestry to bioenergy, agriculture, waste management and recycling, meat and poultry, marine, health, food, chemicals, and aquaculture (Figure 1). Among these sectors, the forestry sector clearly dominates, followed by bioenergy and agriculture.

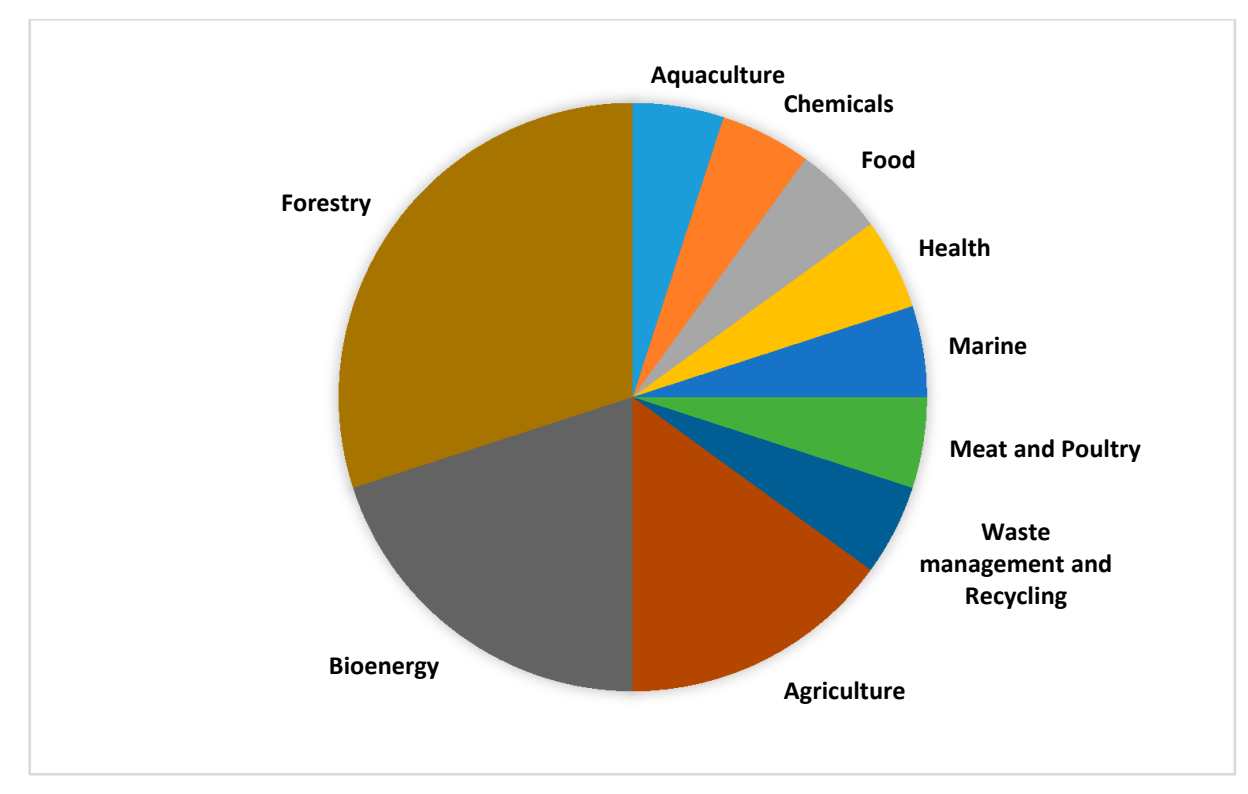

Figure 1. Industrial sectors represented by private firms and industry associations in the public inquiry.

Figure 2 shows that topics relating to the bio-resource vision, such as RD and D in agriculture, forestry, bioenergy, and new bio-based materials, the establishment of new value chains, resource management, and conversion technologies, all receive considerable attention $(62 \%$ of the submissions in the public inquiry). While these issues are discussed across different actor groups, the industry actors and public authorities lead these discussions. The considerable involvement of private actors within the forest sector may reflect the interests these stakeholders have in influencing the direction of the bioeconomy discourse. This sector advocates increased harvesting and the exploitation of biomass resources from the forests, and the expanded use of biomass resources to create, among others, bio-materials, bioenergy and biofuels. This position can be interpreted as an outcome of the uncertainties associated with the crisis in the Norwegian pulp and paper sector, a sector which has practically collapsed in recent years. The industry's main interest is to find alternative uses for timber and forest residuals, and to encourage policy-makers to support and foster investments in 
the sector. The submissions from the energy sector advocate the increased use of bioenergy, and public investments in biofuel development. Some exemplar quotes from the submission of an energy company illustrate the argument:

"Bioenergy will be part of the bioeconomy. A bioeconomy strategy hence needs to include a further development of those parts in the value chain that are already active and commercially available today. It is important that stationary bioenergy and $2 G$ biofuels are among the building blocks in a Norwegian bioeconomy strategy [ ... ] Forest resources are the best raw material for biofuels [... ] Biofuels will increase value creation from the forest by inverting the export of timber and will strengthen the wood manufacturing industry in general." (Energy company)

Biogas technology suppliers focus on competition and market structure, and argue that the public authorities need to take a more active role in creating better market conditions for green and bio-based products. They, therefore, push for a more active and strategic use of demand-side policies, such as public procurement.

"[ ... ] There is a need for markets and cost levels which can compete with fossil based solutions. In order to create new value chains based on biomass stable framework conditions, coordination and support from the public authorities are needed [ ... ] There is enormous potential to produce food and products from the sea [... W We need to find alternative products that can exploit forest resources [ ... ] The solutions build on combining known technologies, but the challenges are related to both technology and profitability." (Industry association)

In addition, public authorities, such as local and regional governments, promote issues associated with the bio-resource vision. Their main focus is on research and innovation, and on the capitalisation of a wide range of bio-resources, which will presumably lead to economic growth and employment opportunities. In particular, they view their role as the promoters of cross-sector collaboration amongst regional actors, typically between industry and universities and research institutes. While positive effects related to sustainability and environment are portrayed implicitly, they are not emphasised as the main outcomes of the development of the bioeconomy. Thus, sustainability aspects receive limited attention from the public policy actors. See the following exemplar quote:

"The development of new value chains requires investments in research and innovation. A national strategy for research and innovation will create the basis for an innovative industrial sector based on national natural resources [... ] The role of the local municipality will be to connect existing competences within biomass utilisation (RED, industrial production, market) and other knowledge sectors/networks (e.g., oil, shipping, finance, defense, and ICT) with the objective to identify new opportunities for value creation and job creation." (Local government)

The bio-technology vision is represented by $23 \%$ of the submissions, emphasising issues related to biotechnology research and the commercialisation of $\mathrm{R}$ and $\mathrm{D}$ within the life sciences and health. Unsurprisingly, it is essentially the academics (universities and research institutes) who are leading the biotechnology/science push discourse. Notably, the issue of life sciences and health-related biotechnology is discussed as having the potential to become a growing field. Their arguments clearly stress the need to develop biotechnology to prevent and treat different diseases, and at the same time, they highlight the many new business opportunities, which may come as a result of the commercialisation of biotechnology. It is assumed that the market for biotechnology products is promising, and that it would be a missed opportunity to neglect this field in a national bioeconomy strategy. A quote from the submission of an industry association illustrates this point:

"Medical and health-related biotechnology needs to be a part of the national bioeconomy strategy. New technology based on gene- and biotechnology has the potential to bring us large opportunities for treatment and prevention of diseases, and at the same time create new business opportunities [...] The market for biotechnology products is large and will become even larger in the years to come." (Industry association) 


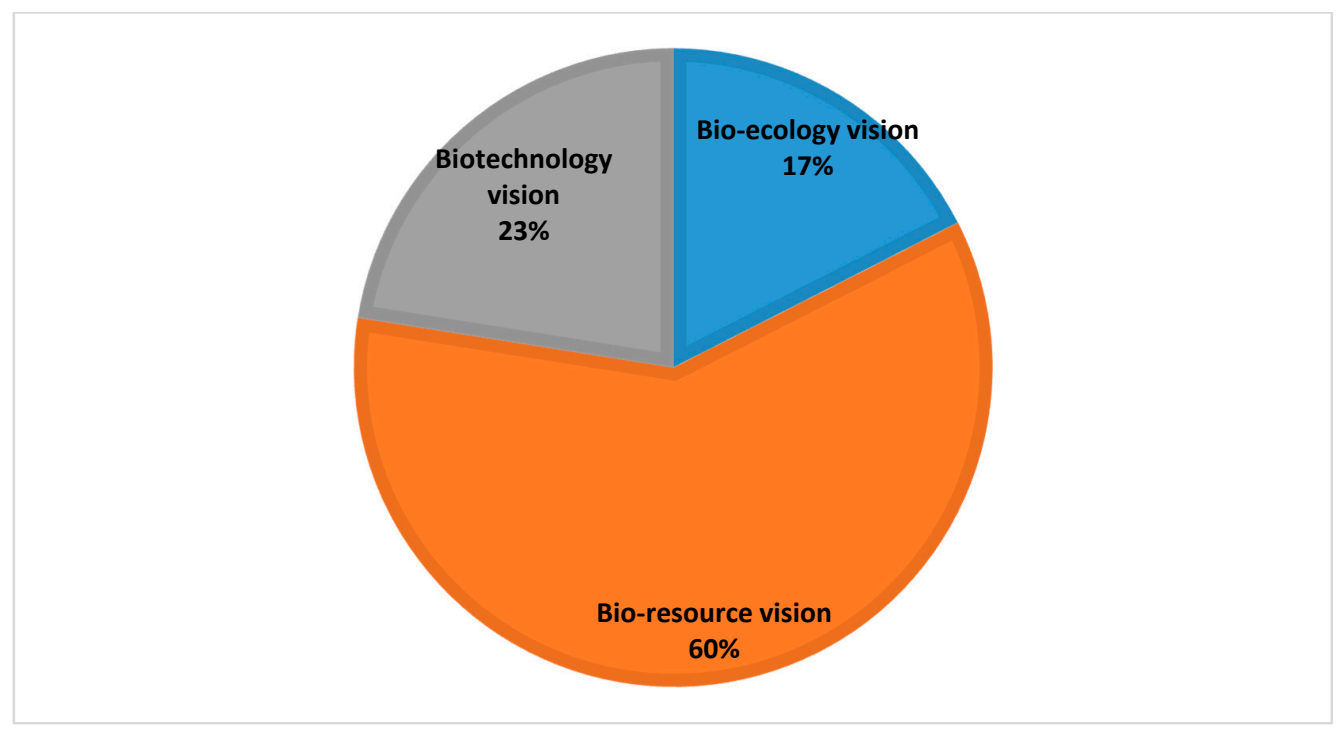

Figure 2. Relative share of bio-economy visions in the public inquiry.

Overall, these submissions express disappointment with the way the government at the outset has defined the scope of the bioeconomy, leaving health-related biotechnology and life sciences out of the definition. An example quote in this regard can be traced back to the submission from a university, which states that:

"[ ... ] Microbal biotechnology is a decisive research field if Norway is to develop economically sustainable and competitive bioprocesses based on Norwegian biomass in the future. Such investment will contribute to increased industrial activity and create new jobs within the bioeconomy." (University)

While the two first visions (i.e., the bio-technology vision and bio-resource vision) share many similar aspects (the focus on technology development, $\mathrm{R}$ and $\mathrm{D}$ and economic growth, employment, market development, etc.), the bio-ecology vision has sustainability as the primary objective of the bioeconomy. The actors within this vision express strong concerns related to sustainability and environmental issues and, at the same time, criticise the capitalisation of public goods, warning about risks related to the over-extraction of biological resources. A quote from an environmental NGO illustrates this argument:

"It is important to have a realistic assessment of how much biomass can be harvested from forests [... I If the forest is to contribute with biomass resources to more than a small part of the potential application areas, much more needs to be harvested than just the forest waste (GROT). And this fact must make us listen to the alarm signals: what implications will this have for biodiversity and recreation? What are the implications for the climate and carbon storage function of the forest? [... We need to set strict requirements for the application of harvested forest biomass, so that it is used as effectively as possible and with highest possible conversion rates. From our viewpoint it is hence not interesting to produce liquid biofuels from forest biomass." (NGO)

The analysis of the material shows that a minority of submissions (14\%) emphasise questions such as environmental preservation, biodiversity, ecosystem services and a circular approach to the bioeconomy. These issues are important predominantly for NGOs and a few industry associations. This perception radically contrasts with arguments from actors that have vested interests in, for instance, forest resources. In this sense, the bio-ecology actors favour the need to protect forest resources and pursue a careful assessment of the actual available biomass resources. They argue against the utilisation of forest biomass resources for the purpose of energy use, and contend that 
estimates of biomass extraction from forests need to be carefully assessed and managed. Moreover, they argue for the need to preserve forest resources, which are seen as public goods, serving important functions in terms of preventing further losses of biodiversity, preserving the essential ecosystem and delivering recreational services:

"There are several opportunities for RED and business development within an increased investment in the bioeconomy, but it requires a holistic perspective on the limitations that exist with regards to the exploitation of raw materials, the quantity of accessible raw material, the need to stop the loss of biodiversity, preservation of landscape qualities, recreational life and other interests in the same areas, and the real consequences of climate change." (NGO)

In addition, we see that perspectives on a circular production mode are represented by new actors from the waste management and recycling industry. This is linked to how the idea of waste has been transformed from a disposable pollutant to an important raw material in manufacturing and energy production. Concepts such as recycling and reuse are increasingly being redefined in terms of waste prevention, future material use and opportunities for the circular economy. The point is illustrated by an industry association:

"It is important from a resource-and climate perspective that the food production and waste from society is reintegrated in the life cycle through the reutilisation of bio-manure from biogas production in agriculture and the production of new food. The EU's vision on a circular economy and our own bioeconomy strategy will be important drivers." (Industry Association)

This last statement suggests that environmental sustainability may increasingly become integrated into new business models in the sector. However, the empirical material at hand is too limited in order to make any general conclusions on this aspect.

\section{Conclusions and Reflections}

The aim of this paper has been to improve our understanding of the politics of socio-technical transitions. The study has been based on an analysis of the different visions and contending rationales of different actors shaping the policy discourse on the bioeconomy. The analysis has been accomplished by applying three visions on the bioeconomy to analyse the content of a recent public inquiry process that sought to inform the direction of a national policy strategy for the bioeconomy in Norway. Although the findings have revealed a substantial diversity in visions and interpretations of the bioeconomy, they also show that the policy positions advocated by the stakeholders, to a large extent, reflect their roles and positions within the dominant regimes of the wider national economy.

Among the three bioeconomy visions, the bio-resource vision dominates the discourse. This finding reflects the traditionally important role of natural resource industries in the Norwegian economy and it is, hence, not that surprising that these sectors' positions on the bioeconomy are central in the material analysed. Still, this may serve as an illustration of how power structures are manifested in the existing socio-technical regime of the resource-driven Norwegian economy, and how these actors actively try to position themselves within the emerging bioeconomy.

It is primarily industry actors and public authorities that promote this vision. Overall, there seems to be a consensus among this group of actors regarding what needs to be prioritised and included in a national bioeconomy strategy. These actors advocate policies enabling the bioeconomy with attention to creating new markets for bio-based products and hence rebalancing the playing field between bio-based products and products based on fossil resources. They promote an increased use of policy instruments, such as the public procurement of bio-based products, in order to stimulate market demand. Their position often highlights the large unexploited potential for utilising biomass resources extracted and harvested nationally. In this context, biomass from forests is seen as having huge potential for the development of a national bioeconomy. According to this view, the state should take a more proactive role in developing new value chains based on biomass from forestry. As we 
have seen, the Norwegian forestry sector has been struggling in recent years and is seeking new ways of exploiting wood resources. In addition to the industrial players, regional governments seem to have a similar vision, focusing on the role of research and innovation and on the capitalisation of a wide range of bio-resources. This position emphasises the capitalisation of natural bio-resources in order to make Norwegian industries more competitive, and to create jobs nationally.

Overall, this position dedicates limited attention towards issues related to sustainability. Sustainability is seen as an effect of the bioeconomy rather than as a main starting point for it or outcome from it. To some extent, these positions hence reflect a "business as usual" approach to the bioeconomy, rather than presenting alternative ways to develop it, or counter-framings to contemporary industrial production practices.

Interpreted through the lens of our conceptual framework, these findings reflect how the incumbent actors of existing socio-technical regimes often try to resist change (e.g., [20]). However, we do not only find that the incumbent actors try to resist change brought about by niche-level actors; we also find that some of the incumbents pro-actively take part in the shaping of the future socio-technical regime of the bioeconomy.

The bio-technology vision, emphasising the application and commercialisation of science and technology, is most frequently advocated by the academic community. Similarly to the arguments put forward by the natural resource industries, they view the bioeconomy as an opportunity to create new businesses based on biotechnology products, and at the same time as an opportunity to make important advances within the treatment and prevention of diseases.

However, these visions based on the development and application of technology and the industrial exploitation of biomass resources are contrasted by sustainability concerns from NGOs arguing for a more careful use of biomass resources. These perspectives, reflecting the bio-ecology vision, highlight how the national bioeconomy strategy should take into account the relationship between biomass utilisation and sustainability, and make sure that the activities within the bioeconomy minimise negative environmental impacts. This group of actors represents a minority of the submissions to the public inquiry. The bio-ecology vision, hence, represents a contending alternative to the other two visions in how they portray and bring sustainability into the bioeconomy discourse.

Overall, the analysis has shown that the conceptual framework consisting of the three visions of the bioeconomy, applied onto the submissions in the national hearing process, has proved to be a relevant and appropriate tool. The study has categorised the different submissions into the three respective visions, and the conceptual framework has thereby helped clarify how the different submissions express and represent diverging perspectives on the bioeconomy. This said, there seems to be extensive agreement across the various submissions in terms of seeing the bioeconomy as an opportunity to address societal challenges such as climate change. The divergence of perspectives rather relates to the means by which these societal challenges should be addressed.

The contending visions observed among the public submissions illustrate how socio-technical transitions often comprise competing points of view and values. The paper has illustrated how the different responses to the public inquiry may contribute to a destabilisation of the existing (fossil) regime; whereas some of the actors in the existing regime opposes the new possibilities of the circular and sustainable bioeconomy, others embrace these and wish to contribute to the shaping of an alternative regime. This may cause a shift in the power balance between the various stakeholders involved. In particular, the policy strategy on the bioeconomy needs to deal with emerging tensions, such as the balance and relationship between economic growth and sustainability.

In this sense, the paper has illustrated the relevance of the transformational policy framework of Weber and Rohracher [15], in terms of how giving direction to a socio-technical transition can be complicated by coordinating and balancing the different interests and stakeholders involved. Still, it remains crucial to ensure broad and democratic involvement and reflexivity across different stakeholders and interests in the process of shaping the bioeconomy of tomorrow. 
Acknowledgments: We want to thank the EnergiX programme and the Bionær programme at the Research Council of Norway for financial support through the ETIS project and the SusValueWaste project. The usual disclaimers apply.

Author Contributions: Lisa Scordato and Markus M. Bugge conceived and designed the research; Lisa Scordato undertook the primary research and analysis of the data and was the main author of Section 5; Markus M. Bugge was the main author of Section 2; Arne Fevolden was the main author of Section 4; all authors contributed to the writing of the paper. All authors read and approved the final manuscript.

Conflicts of Interest: The authors declare no conflict of interest.

\section{References}

1. German Bioeconomy Council. Synopsis of National Strategies around the World; Office of the Bioeconomy Council: Berlin, Germany, 2015.

2. Staffas, L.; Gustavsson, M.; McCormick, K. Strategies and Policies for the Bioeconomy and Bio-Based Economy: An Analysis of Official National Approaches. Sustainability 2013, 5, 2751-2769. [CrossRef]

3. Bugge, M.; Hansen, T.; Klitkou, A. What is the Bioeconomy? A Review of the Literature. Sustainability 2016, 8, 691. [CrossRef]

4. Mazzucato, M. The Entrepreneurial State: Debunking Public vs. Private Sector Myths; Anthem Press: London, UK, 2013.

5. Weber, K.M.; Rohracher, H. Legitimizing research, technology and innovation policies for transformative change: Combining insights from innovation systems and multi-level perspective in a comprehensive 'failures' framework. Res. Policy 2012, 41, 1037-1047. [CrossRef]

6. Geels, F.W. Technological transitions as evolutionary reconfiguration processes: A multi-level perspective and a case-study. Res. Policy 2002, 31, 1257-1274. [CrossRef]

7. Kemp, R.; Schot, J.; Hoogma, R. Regime shifts to sustainability through processes of niche formation: The approach of strategic niche management. Technol. Anal. Strateg. Manag. 1998, 10, 175-198. [CrossRef]

8. Kuhlmann, S.; Rip, A. The Challenge of Addressing Grand Challenges-A Think Piece on How Innovation Can Be Driven towards the "Grand Challenges" as Defined under the Prospective European Union Framework Programme Horizon 2020; University of Twente: Enschede, The Netherlands, 2014.

9. Schot, J.; Steinmueller, E. Framing Innovation Policy for Transformative Change: Innovation Policy 3.0; SPRU Science Policy Research Unit, University of Sussex: Brighton, UK, 2016.

10. European Commission. Horizon 2020-The Framework Programme for Research and Innovation Communication from the European Commission; European Commission: Brussels, Belgium, 2011.

11. European Commission. Responsible Research and Innovation. Europe's Ability to Respond to Societal Challenges; European Commission: Brussels, Belgium, 2012.

12. Stirling, A. "Opening Up" and "Closing Down" Power, Participation, and Pluralism in the Social Appraisal of Technology. Sci. Technol. Hum. Values 2008, 33, 262-294. [CrossRef]

13. Martin, B. Twenty Challenges for Innovation Studies; University of Sussex: Brighton, UK, 2015.

14. Klein Woolthuis, R.; Lankhuizen, M.; Gilsing, V. A system failure framework for innovation policy design. Technovation 2005, 25, 609-619. [CrossRef]

15. Geels, F.W. From sectoral systems of innovation to socio-technical systems-Insights about dynamics and change from sociology and institutional theory. Res. Policy 2004, 33, 897-920. [CrossRef]

16. Geels, F.W. Processes and patterns in transitions and system innovations: Refining the co-evolutionary multi-level perspective. Technol. Forecast. Soc. Chang. 2005, 72, 681-696. [CrossRef]

17. Geels, F.W.; Schot, J. Typology of sociotechnical transition pathways. Res. Policy 2007, 36, 399-417. [CrossRef]

18. Schot, J.; Geels, F.W. Strategic niche management and sustainable innovation journeys: Theory, findings, research agenda, and policy. Technol. Anal. Strateg. Manag. 2008, 20, 537-554. [CrossRef]

19. Turnheim, B.; Geels, F.W. The destabilisation of existing regimes: Confronting a multi-dimensional framework with a case study of the British coal industry (1913-1967). Res. Policy 2013, 42, 1749-1767. [CrossRef]

20. Geels, F.W. Regime Resistance against Low-Carbon Transitions: Introducing Politics and Power into the Multi-Level Perspective. Theory Cult. Soc. 2014, 31, 21-40. [CrossRef]

21. Smith, A.; Stirling, A.; Berkhout, F. The governance of sustainable socio-technical transitions. Res. Policy 2005, 34, 1491-1510. [CrossRef] 
22. Shove, E.; Walker, G. CAUTION! Transitions ahead: Politics, practice, and sustainable transition management. Environ. Plan. A 2007, 39, 763-770. [CrossRef]

23. Meadowcroft, J. Engaging with the politics of sustainability transitions. Environ. Innov. Soc. Transit. 2011, 1, 70-75. [CrossRef]

24. Smith, A.; Raven, R. What is protective space? Reconsidering niches in transitions to sustainability. Res. Policy 2012, 41, 1025-1036. [CrossRef]

25. Markard, J.; Raven, R.; Truffer, B. Sustainability transitions: An emerging field of research and its prospects. Res. Policy 2012, 41, 955-967. [CrossRef]

26. Ollikainen, M. Forestry in bioeconomy-Smart green growth for the humankind. Scand. J. For. Res. 2014, 29, 360-366. [CrossRef]

27. Pülzl, H.; Kleinschmit, D.; Arts, B. Bioeconomy-An emerging meta-discourse affecting forest discourses? Scand. J. For. Res. 2014, 29, 386-393. [CrossRef]

28. Richardson, B. From a fossil-fuel to a biobased economy: the politics of industrial biotechnology. Environ. Plan. C Gov. Policy 2012, 30, 282-296. [CrossRef]

29. Levidow, L.; Birch, K.; Papaioannou, T. EU-agri-innovation policy: Two contending visions of the bio-economy. Crit. Policy Stud. 2012, 6, 40-65. [CrossRef]

30. Birch, K.; Levidow, L.; Papaioannou, T. Sustainable capital? The Neoliberalization of Nature and Knowledge in the European "Knowledge-based Bio-Economy". Sustainability 2010, 2, 2898-2918. [CrossRef]

31. Birch, K. Emergent imaginaries and fragmented policy frameworks in the Canadian bio-econoy. Sustainability 2016, 8, 1007. [CrossRef]

32. De Witt, A.; Osseweijer, P.; Pierce, R. Understanding public perceptions of biotechnoogy through the "Integrative Worldview Framework". Public Underst. Sci. 2015. [CrossRef]

33. De Besi, M.; McCormick, K. Towards a Bioeconomy in Europe: National, Regional and Industrial Strategies. Sustainability 2015, 7, 10461-10478. [CrossRef]

34. Bosman, R.; Rotmans, J. Transition governance towards a Bioeconomy: A Comparison of finland and the Netherlands. Sustainability 2016, 8, 1017. [CrossRef]

35. Hilgartner, S. Making the Bioeconomy Measurable: Politics of an Emerging Anticipatory Machinery. BioSocieties 2007, 2, 382-386. [CrossRef]

36. Pollack, A. White House Promotes a Bioeconomy. New York Times, 26 April 2012.

37. Zilberman, D.; Kim, E.; Kirschner, S.; Kaplan, S.; Reeves, J. Technology and the future bioeconomy. Agric. Econ. 2013, 44, 95-102. [CrossRef]

38. Marsden, T. Towards a Real Sustainable Agri-food Security and Food Policy: Beyond the Ecological Fallacies? Political Q. 2012, 83, 139-145. [CrossRef]

39. Thornton, P.H.; Ocasio, W. Institutional logics. In Organizational Institutionalism; Greenwood, R., Oliver, C., Sahlin, K., Suddaby, R., Eds.; Sage Publications: London, UK, 2008; pp. 99-129.

40. Ville, S.; Wicken, O. The dynamics of resource-based economics development: Evidence from Australia and Norway. Ind. Corp. Chang. 2012, 22, 1341-1371. [CrossRef]

41. Ryggvig, H. Statoil, Stoltenberg og den Nye Norske Imperialismen. Available online: http://intsos.no/?id= 3291 (accessed on 17 January 2017).

42. Doloreux, D.; Isaksen, A.; Aslesen, H.W.; Melançon, Y. A Comparative Study of the Aquaculture Innovation Systems in Quebec's Coastal Region and Norway. Eur. Plan. Stud. 2009, 17, 963-981. [CrossRef]

43. Klitkou, A. Innovasjon i Matvare- og Skogsektoren i Norge; NIFU: Oslo, Norway, 2010.

(C) 2017 by the authors; licensee MDPI, Basel, Switzerland. This article is an open access article distributed under the terms and conditions of the Creative Commons Attribution (CC BY) license (http:/ / creativecommons.org/licenses/by/4.0/). 